\title{
Neurons of the Dopaminergic/Calcitonin Gene-Related Peptide A11 Cell Group Modulate Neuronal Firing in the Trigeminocervical Complex: An Electrophysiological and Immunohistochemical Study
}

\author{
Annabelle R. Charbit, Simon Akerman, Philip R. Holland, and Peter J. Goadsby \\ Headache Group, Department of Neurology, University of California, San Francisco, San Francisco, California 94143
}

\begin{abstract}
Activation of spinal trigeminal afferents innervating the cranial vasculature is likely to play a role in migraine, although some parts of the clinical presentation may have a dopaminergic basis. The A11 nucleus, located in the posterior hypothalamus, provides the only known source of descending dopaminergic innervation for the spinal gray matter. Extracellular recordings were made in the trigeminocervical complex (TCC) in response to electrical stimulation of the dura mater. Receptive fields were characterized by mechanical noxious and innocuous stimulation of the ipsilateral ophthalmic dermatome. Stimulation of the A11 significantly inhibited peri-middle meningeal artery dural and noxious pinch evoked firing of neurons in the TCC. This inhibition was reversed by the $\mathrm{D}_{2}$ receptor antagonist eticlopride. Lesioning of the A11 significantly facilitated dural and noxious pinch and innocuous brush evoked firing from the TCC. In previous work using immunohistofluorescence, it was shown that $\mathrm{D}_{1}$ and $\mathrm{D}_{2}$ receptors were found in the rat TCC, and here we report, in addition, that $\mathrm{D}_{4}$ and $\mathrm{D}_{5}$ dopamine receptors are also present, whereas $\mathrm{D}_{3}$ receptors are not. No dopamine receptors were present in the A11 nucleus itself. However, the A11 does contain dopamine and calcitonin gene-related peptide (CGRP) and, by this combination, is distinct from the neighboring CGRPergic subparafascicular nucleus. Exploration of dopaminergic influences and mechanisms in migraine may open up an almost untapped opportunity to pursue potential new therapeutic options for the disorder.
\end{abstract}

\section{Introduction}

Migraine is a common, chronic, often incapacitating brain disorder characterized by attacks of severe headache, with sensitivity to sensory stimuli, such as light and sound, and in some cases neurologic symptoms called aura (Goadsby et al., 2002; Headache Classification Committee of the International Headache Society, 2004). Allodynia, whereby innocuous stimuli are felt as painful, is a common feature of migraine that requires additional understanding (Selby and Lance, 1960; Burstein et al., 2000a; Bigal et al., 2008).

Migraine involves activation of the trigeminovascular system (Goadsby et al., 2002). This activation is associated with release of calcitonin gene-related peptide (CGRP) (Goadsby et al., 1988, 1990; Juhasz et al., 2003), which itself can trigger migraine (Lassen et al., 2008 ), is involved in activation of neurons in the trigeminocervical complex (Storer et al., 2004), and blockade of its effects is effective in acute migraine (Olesen et al., 2004; Ho et al., 2008). Trigeminal primary afferents innervating dural vessels are mainly

\footnotetext{
Received June 18, 2009; accepted Aug. 21, 2009.

A.R.C. was funded by a prize PhD studentship awarded by the Brain Research Trust. We acknowledge the excellent technical assistance of Michele Lasalandra and early technical advice of Astrid Bergerot.

Correspondence should be addressed to Prof. Peter J. Goadsby, Headache Group, Department of Neurology, University of California, San Francisco, 505 Parnassus Avenue, San Francisco, CA 94143-0114. E-mail: peter.goadsby@ucsf.edu.

DOI:10.1523/JNEUROSCI.2887-09.2009

Copyright $\odot 2009$ Society for Neuroscience $\quad 0270-6474 / 09 / 2912532-10 \$ 15.00 / 0$
}

nociceptive $\mathrm{A} \delta$ - and C-fibers of the ophthalmic (first) division of the trigeminal nerve (Feindel et al., 1960).

Dopamine fibers and terminals are located throughout the spinal gray matter (Strassman et al., 1996), as are dopamine receptors (Levant and McCarson, 2001). Furthermore, $\mathrm{D}_{1}$ and $\mathrm{D}_{2}$ dopamine receptors have been identified in the trigeminocervical complex (TCC) (Bergerot et al., 2007). Additionally dopamine exerts antinociceptive effects when microiontophoresed directly into the TCC (Bergerot et al., 2007). It has therefore been hypothesized that dopamine binds inhibitory $\mathrm{D}_{2}$-like receptors in the TCC and prevents transmission of nociceptive signals (Bergerot et al., 2007).

In the spinal cord, nociceptive signaling is modulated in part by descending systems from the hypothalamus (FleetwoodWalker et al., 1988; Workman and Lumb, 1997; Holden and Naleway, 2001), so it is likely that the hypothalamus also sends inhibitory projections to the TCC. One possible hypothalamic candidate is the dopaminergic A11 nucleus, which sends direct inhibitory projections to the spinal cord dorsal horn (Takada et al., 1988). The A11 nucleus sits close to the third ventricle and is distributed along the rostrocaudal axis, in the periventricular posterior region of the hypothalamus and the periventricular gray of the caudal thalamus (Dahlstrom and Fuxe, 1964). The A11 was found to contain dopamine cells (Dahlstrom and Fuxe, 1964; Takada et al., 1988) and, more recently, dopamine cells colocalized with CGRP (Orazzo et al., 1993), as well as CGRP-only cells (Yasui et al., 1989, 1991).

As yet, there is no evidence linking specific dopaminergic nuclei and migraine, but since the A11 provides the only known 
source of descending dopaminergic innervation for the spinal gray matter (Holstege et al., 1996), we hypothesized that A11 projections would also have a descending modulatory effect on nociceptive trigeminovascular traffic. We used a durovascular model that has been highly predictive of translational outcomes in migraine (Bergerot et al., 2006) to test this question. Additionally, because CGRP has been reported in both the A11 and the neighboring subparafascicular nucleus (Spf) (Yasui et al., 1989, 1991; Orazzo et al., 1993), and the literature is inconsistent about whether the Spf is part of the A11 nucleus (Takada et al., 1988), we used immunohistochemistry to characterize the area. We also determined which dopamine receptor subtypes are present in the rat TCC and in the A11 nucleus. This work was presented in preliminary form at the Ninth International Headache Congress (Stockholm, June 2007) (Charbit et al., 2007).

\section{Materials and Methods Surgery}

All experiments were conducted under either the United Kingdom Home Office Animals (Scientific Procedures) Act (1986) or in accordance with guidelines of the University of California, San Francisco, Institutional Animal Care and Use Committee. A total of 36 male Sprague Dawley rats (250-450 g) were anesthetized for the experiments. Anesthesia was induced with intraperitoneal pentobarbitone sodium (Sigma-Aldrich), $60 \mathrm{mg} \mathrm{kg}^{-1}$ in saline, and maintained by slow intravenous infusion of propofol (Rapinovet; Schering-Plough Animal Health), $20-25 \mathrm{mg} \mathrm{kg}^{-1} \mathrm{~h}^{-1}$. A sufficient depth of anesthesia was judged from the absence of withdrawal reflexes in the nonparalyzed state or from fluctuations in blood pressure during muscular paralysis. The left femoral artery and vein were exposed and cannulated for blood pressure recording and intravenous infusion of anesthetic, respectively. The rats were paralyzed with $1 \mathrm{mg} \mathrm{kg}^{-1}$ pancuronium bromide (Pavulon; Organon) and ventilated with oxygen-enriched air, $2 \mathrm{ml}, 80-100$ strokes per minute (model 7025; Ugo Basile). End-tidal $\mathrm{CO}_{2}$ was monitored (Capstar 100; CWE) and maintained between 2.8 and 4.5\%. Body temperature was monitored via a rectal thermometer and kept within physiological range at $36.9-37.9^{\circ} \mathrm{C}$, using a homeothermic blanket system (homeothermic blanket system for rodents; Harvard Instruments). Arterial blood gas parameters were measured on completion of surgery and fell inside normal physiological parameters for rats, $\mathrm{pH}$ $7.35-7.45 ; \mathrm{pCO}_{2}, 2.7-5.7 \mathrm{kPa} ; \mathrm{pO}_{2}, 8-25 \mathrm{kPa}$. At the end of the experiment, animals were killed with an overdose of anesthetic (pentobarbitone, $0.7 \mathrm{ml}$ of $200 \mathrm{mg} \mathrm{ml}^{-1}$ ).

The rats were placed in a stereotaxic frame (model 1600 stereotaxic frame; David Kopf Instruments), the skull was exposed, and a craniotomy of the left parietal bone was performed with a saline-cooled drill (MF-Perfecta with 945 hand piece; W\&H) to expose the middle meningeal artery, which was then bathed in mineral oil to prevent dehydration. The skin and muscles of the dorsal neck were incised and separated, and a full $\mathrm{C}_{1}$ laminectomy was performed. The underlying dura mater was incised (ophthalmic scissors; Fine Scientific Tools) and removed to expose the dorsal spinal cord. An additional craniotomy was performed above the stereotaxic coordinates of the A11 nucleus (Paxinos and Watson, 2005), targeting the larger, rostral part [anteroposterior (AP), $5.50 \mathrm{~mm}$; dorsoventral (DV), $2.00 \mathrm{~mm}$; mediolateral (ML), $0.50 \mathrm{~mm}$ ]. As these coordinates fall beside the midline, the superior sagittal sinus was fully exposed to allow a clear view of the midline coordinates. The underlying dura mater was pierced to allow penetration of the stimulating electrode.

\section{Electrical stimulation of the peri-middle meningeal artery dura mater and recording from TCC}

A bipolar stimulating electrode (NE-200; Harvard Apparatus) was placed directly onto the dura mater, adjacent to or straddling the middle meningeal artery, and square-wave stimuli $(0.6 \mathrm{~Hz})$ of $0.5 \mathrm{~ms}$ duration and 8-16 V applied (Grass S88; Grass Instruments). Extracellular recordings were made in the ipsilateral TCC from neurons with $\mathrm{A} \delta$ - or $\mathrm{C}$-fiber, or both, latency, responding to both electrical stimulation of the dura and mechanical noxious and innocuous stimulation of the facial receptive field, using a tungsten microelectrode of impedance $0.5-2 \mathrm{M} \Omega$ and tip diameter of $0.5 \mu \mathrm{m}$ (tungsten metal microelectrode; Harvard Apparatus). The recording electrode, suspended on a piezoelectric microdrive (EXFO; Burleigh Products) attached to the stereotaxic frame, was driven by a controller (EXFO Controller 8200; Inchworm). As the electrode was lowered, neurons encountered were tested for convergent input from the cutaneous receptive field, using noxious pinch and innocuous brush, and using electrical stimulation from the dura mater. The signal from the recording electrode was fed through an AC preamplifier (Neurolog NL104; gain, 2000×; Digitimer), through filters (Neurolog NL125; bandwidth, $300 \mathrm{~Hz}$ to $20 \mathrm{kHz}$ ) and a noise eliminator (Humbug; Quest Scientific), and through a second stage amplifier (Neurolog NL106; gain, 200-999×). The filtered and amplified electrical signal was routed to a loudspeaker, via a power amplifier (Neurolog NL120), and was displayed on analog and digitalstorage oscilloscopes (Goldstar; LG Precision; Metrix Electronics). The signal was also fed to a gated amplitude discriminator (Neurolog NL201) and then into a window discriminator, which displayed a single voltage pulse (or spike) of given height and duration in response to each action potential whose height fell within a preset window. The window discriminator output data were then displayed on a computer as either a peristimulus histogram or a poststimulus histogram.

\section{Stimulation and lesioning of the A11 nucleus}

A unipolar tungsten metal electrode (WPI) was plunged directly into the chosen stereotaxic coordinates for the A11 (AP, $5.50 \mathrm{~mm}$; DV, $2.00 \mathrm{~mm}$; ML, $0.45 \mathrm{~mm}$ ). A pulse generator (Neurolog NL301) divided by a pulse buffer (Neurolog NL510) activated a constant current stimulus isolator (Neurolog NL800A).

\section{Drugs}

The $\mathrm{D}_{2}$-like receptor antagonist $S$-(-)-eticlopride hydrochloride (SigmaAldrich) was dissolved in water for injection and administered at a dose of $3 \mathrm{mg} \mathrm{kg}^{-1}$ (Missale et al., 1998). The drug was made fresh on the morning of the experiment and given at a volume of $0.3 \mathrm{ml}$.

\section{Experimental protocols}

Neuronal characterization. The recording electrode was advanced through the spinal cord, and the receptive field was assessed in all three trigeminal territories. The first step was to identify a neuron sensitive to stimulation of the ophthalmic dermatome of the trigeminal nerve (V1) receiving convergent input from the dura mater. Three stable baseline responses were then recorded to peri-middle meningeal artery dural stimulation $(8-16 \mathrm{~V}, 0.5 \mathrm{~ms}, 0.6 \mathrm{~Hz}$ for 20 sweeps) and cutaneous receptive field stimulation. Stimulation and recording parameters then remained constant throughout the experiment. Peristimulus histograms were used for observing the evoked firing in response to noxious and innocuous cutaneous stimulation (pinch and brush) of the ophthalmic dermatome, and poststimulus histograms were used for viewing units firing in response to dural electrical stimulation.

A11 nucleus stimulation. The ipsilateral A11 was electrically stimulated (5-50 $\mu \mathrm{A}, 0.5 \mathrm{~ms}$ duration, and $2-100 \mathrm{~Hz}$ ) during TCC recording in response to stimulation of the dura mater and cutaneous receptive field, and the effect of A11 stimulation on evoked neuronal firing in the TCC was observed $(n=16)$. A11 stimulation parameters were varied for each experiment to optimize changes in TCC firing. In a subset of experiments $(n=5)$, the $\mathrm{D}_{2}$-like receptor antagonist $S$ - $(-)$-eticlopride was administered $\left(3 \mathrm{mg} \mathrm{kg}^{-1}\right.$, i.v.), and the effect of the drug on the response of evoked firing to A11 stimulation was monitored at 5 or 10 min intervals over $40 \mathrm{~min}$. In an additional set of experiments $(n=7)$, the $\mathrm{D}_{2}$-like receptor antagonist $S$-(-)-eticlopride was administered $\left(3 \mathrm{mg} \mathrm{kg}^{-1}\right.$, i.v.), and the effect of the drug on evoked firing in the TCC with no A11 intervention was monitored at $5 \mathrm{~min}$ intervals for $40 \mathrm{~min}$. Control experiments $(n=5)$ were performed in a separate group of animals, in which saline was intravenously administered at the same volume as $S$-(-)-eticlopride $(0.3 \mathrm{ml})$, and evoked firing was observed at $5 \mathrm{~min}$ intervals for $40 \mathrm{~min}$. 
Microinjection of L-glutamate into the A11 nucleus. To explore the possibility that fibers of passage were activated during electrical stimulation, L-glutamate ( $210 \mathrm{nl} ; n=7)$ or vehicle control, saline $(210-250 \mathrm{nl} ; n=6)$, was microinjected into the A11, using a glass micropipette positioned in the A11 nucleus, and the effect on evoked neuronal firing in the TCC in response to stimulation of the dura mater and cutaneous receptive field, was observed at $5 \mathrm{~min}$ intervals for $40 \mathrm{~min}$.

A11 nucleus lesioning. The ipsilateral A11 nucleus was electrically lesioned ( $200 \mu \mathrm{A}, 0.5 \mathrm{~ms}, 20 \mathrm{~Hz}$ for a total duration of $2-3 \mathrm{~min}$ ), and the effect on evoked firing in the TCC was observed at 5 min intervals for 40 $\min (n=8)$. An increase in the lesioning parameters $(>200 \mu \mathrm{A}$, or $>20$ $\mathrm{Hz}$, or for a total duration of $>3 \mathrm{~min}$ ) resulted in cell death in the trigeminal nucleus and abortion of the experiment. Additionally, a sudden blood pressure increase occurred, when both the current and frequency were increased above these parameters, and with the electrode correctly in the A11, so an increase in the parameters was momentarily allowed $(<5 \mathrm{~s})$, to confirm the correct placement of a functioning electrode. Sham experiments $(n=5)$ were performed in a separate group of animals in which the lesioning electrode was placed in the ipsilateral A11 and was not activated, and evoked firing was observed at $5 \mathrm{~min}$ intervals for $40 \mathrm{~min}$.

\section{Data analysis}

Cells that fired with a poststimulation latency of 5-20 ms were classified as being activated by $A \delta$-fiber inputs and those that fired with a latency of $30-60 \mathrm{~ms}$ were classified as being activated by C-fiber inputs. At the start of each experiment, three consistent baseline recordings of trigeminal firing evoked by stimulation of the peri-middle meningeal dura mater and cutaneous receptive fields (noxious pinch and innocuous brush) were made. All subsequent data were normalized and expressed as a percentage of those baselines. To test for an effect of frequency or amplitude of stimulation, the data were collapsed across the animals tested and linear regression applied. ANOVA for repeated measures was performed on data with pharmacological intervention or A11 lesioning. Bonferroni's post hoc correction for multiple comparisons was used routinely. If Mauchly's test of sphericity was violated appropriately degrees of freedom according to Greenhouse-Geisser are reported (SPSS, version 14). Student's paired $t$ test with post hoc correction was used to test for the individual time points of significance, using the average of the three baselines for comparison, and all data are expressed as the mean \pm SEM. Significance was assessed at the $p<0.05$ level.

\section{Postsurgical examination of tissue}

In all experiments, the recording site was marked by lesioning the TCC $(10-20 \mu \mathrm{A}, 20 \mathrm{~Hz}, 0.5 \mathrm{~ms}$ for $120 \mathrm{~s})$ just before terminal anesthesia. In A11 stimulation experiments, a lesion was also made in the A11 $(100 \mu \mathrm{A}$, $20 \mathrm{~Hz}, 0.5 \mathrm{~ms}$ for $120 \mathrm{~s}$ ). After perfusion and fixation with formaldehyde (4\%) solution, the brain was removed and coronal sections $(60 \mu \mathrm{m}$ thick) were cut and visualized under a light microscope (Zeiss; Axioplan Microscope). Using the rat brain atlas (Paxinos and Watson, 2005) for reference, lesion marks identified the locations of both the recording electrode in the TCC and the stimulating electrode in the A11.

To further determine the location of the stimulating electrode in the A11 dopaminergic cell group, some of the coronal sections were immunostained with antibodies specific to tyrosine hydroxylase (TH) (1:1000 anti-TH; raised in rabbit; Millipore Bioscience Research Reagents), the enzyme that converts tyrosine to L-DOPA in the synthesis of dopamine (Nagatsu and Stjarne, 1998). Dopamine also acts as a precursor to the norepinephrine and epinephrine, so a subset of tissue sections were double-stained with antibodies specific to dopamine- $\beta$-hydroxylase (DBH) (1:300; raised in mouse; Millipore Bioscience Research Reagents), the enzyme that coverts dopamine to norepinephrine (Nagatsu and Stjarne, 1998). The presence of TH and the absence of DBH were used to identify the area as purely dopaminergic.

\section{Immunohistofluorescence characterization of the A11 and trigeminocervical complex}

Male Sprague Dawley rats $(n=8)$ weighing 300-400 g were deeply anesthetized with sodium pentobarbital (Lethobarb; $80 \mathrm{mg} / \mathrm{kg}$ ) and tran- scardially perfused with cold $1 \%$ heparinized saline solution, followed by $4 \%$ formaldehyde. The lower brainstem was removed and postfixed in the same fixative for $1 \mathrm{~h}$ at room temperature, and then cryopreserved at $4^{\circ} \mathrm{C}$, in a $30 \%$ sucrose solution, and left to sit until saturated. Serial coronal sections ( $40 \mu \mathrm{m}$ thick), from the caudal to the rostral A11, and from the cervical spinal cord to the rostral medulla, were cut and collected in a free-floating state.

\section{Dopamine and CGRP}

For characterization of dopamine and CGRP in the A11/subparafasicular area, A11 coronal sections were reacted with the antibody specific to $\mathrm{TH}$, and then double-stained with an antibody specific to CGRP. Both reactions were by direct immunofluorescence. After $1 \mathrm{~h}$ incubation at room temperature in blocking solution $\mathrm{PB}++$ (phosphate buffer containing $0.5 \%$ Triton X-100 and 5\% normal goat serum), the sections were incubated overnight with a solution of antibody specific to TH (1:1000 anti$\mathrm{TH}$; raised in rabbit; Millipore Bioscience Research Reagents) made up in $\mathrm{PB}+$ (phosphate buffer containing $0.5 \%$ Triton X-100 and 2\% normal goat serum). This was followed by three washes with $\mathrm{PB}$ and incubation for $2 \mathrm{~h}$ at room temperature with fluorescent secondary antibody (1:500 anti-rabbit conjugated with fluorescein; raised in goat; Vector Laboratories) in $\mathrm{PB}+$. After washes in $\mathrm{PB}$, the sections were incubated for $1 \mathrm{~h}$ at room temperature in blocking solution $\mathrm{PB}++$ (phosphate buffer containing $0.5 \%$ Triton X-100 and 5\% normal donkey serum), followed by overnight incubation in a solution of antibody specific to CGRP (1:1000 anti-CGRP; raised in sheep; Abcam), in $\mathrm{PB}+$ (phosphate buffer containing $0.5 \%$ Triton X-100 and 2\% normal donkey serum). This was followed by three washes with $\mathrm{PB}$ and incubation for $2 \mathrm{~h}$ at room temperature with fluorescent secondary antibody (1:400 anti-sheep conjugated with AlexaFluor-568; raised in donkey; Vector Laboratories) in PB+.

\section{Dopamine receptors}

For characterization of dopamine receptors, TCC sections were reacted with antibodies specific to $\mathrm{D}_{3}, \mathrm{D}_{4}$, or $\mathrm{D}_{5}$ receptors. Antibodies specific to $\mathrm{D}_{2}$ receptors were used as a positive control, as $\mathrm{D}_{2}$ had been demonstrated to be more abundant than $\mathrm{D}_{1}$ receptors in the TCC (Bergerot et al., 2007). Al1 sections were reacted with antibodies specific to $D_{1}, D_{2}$, $\mathrm{D}_{3}, \mathrm{D}_{4}$, and $\mathrm{D}_{5}$ receptors. We selected antibodies that have previously been proven by Western blot analyses to identify specifically their target proteins: $\mathrm{D}_{1}$ (Huang et al., 1992), $\mathrm{D}_{2}, \mathrm{D}_{3}, \mathrm{D}_{4}$ (Mignini et al., 2000), and $\mathrm{D}_{5}$ (McKenna et al., 2002) receptors. Our reactions were then performed using indirect immunofluorescence. After $1 \mathrm{~h}$ incubation at room temperature in a blocking solution of $\mathrm{PB}++[$ phosphate buffer containing $0.5 \%$ Triton X-100 (Sigma-Aldrich) and 5\% normal goat serum (Millipore)], followed by a two-step avidin-biotin blocking solution (Vector Laboratories) for 30 min to block nonspecific binding sites, the sections were incubated overnight with a solution of antibody specific to $D_{1}(8$ $\mu \mathrm{g} / \mathrm{ml}$; raised in rabbit; Millipore Bioscience Research Reagents), $\mathrm{D}_{2}$ (1:12,000; raised in rabbit; Calbiochem), $\mathrm{D}_{3}$ (1:5000; raised in rabbit; Calbiochem), $\mathrm{D}_{4}$ (1:3000; raised in rabbit; Calbiochem), or $\mathrm{D}_{5}(1: 1000$; raised in rabbit; Calbiochem) receptors made up in $\mathrm{PB}+$ (phosphate buffer containing $0.5 \%$ Triton X-100 and $2 \%$ normal goat serum). This was followed by three washes with $\mathrm{PB}$ and incubation for $2 \mathrm{~h}$ at room temperature with biotinylated secondary antibody (1:500 anti-rabbit; raised in goat; Vector Laboratories) in $\mathrm{PB}+$. After washes in $\mathrm{PB}$, the sections were incubated for $30 \mathrm{~min}$ with an avidin biotinylated peroxidase complex (Vector Laboratories), washed, and further incubated with the biotinylated tyramide solution (PerkinElmer). Finally, sections were incubated for $1 \mathrm{~h}$ at room temperature with avidin coupled to fluorescein isothiocyanate (1:500; Vector Laboratories) in $\mathrm{PB}+$.

\section{Receptor localization: soma versus fibers}

To confirm the location of dopamine receptors in neurons, these sections were double-stained using direct immunofluorescence with an antibody specific to DNA-binding neuron-specific nuclear protein (NeuN), which is present in the soma of most CNS and PNS neurons (Wolf et al., 1996; Polgár et al., 2005). After the blocking step in $\mathrm{PB}++$, the sections were incubated in primary antibody (1:500 anti-NeuN; raised in mouse; Millipore Bioscience Research Reagents) in $\mathrm{PB}+$, washed, and then incu- 

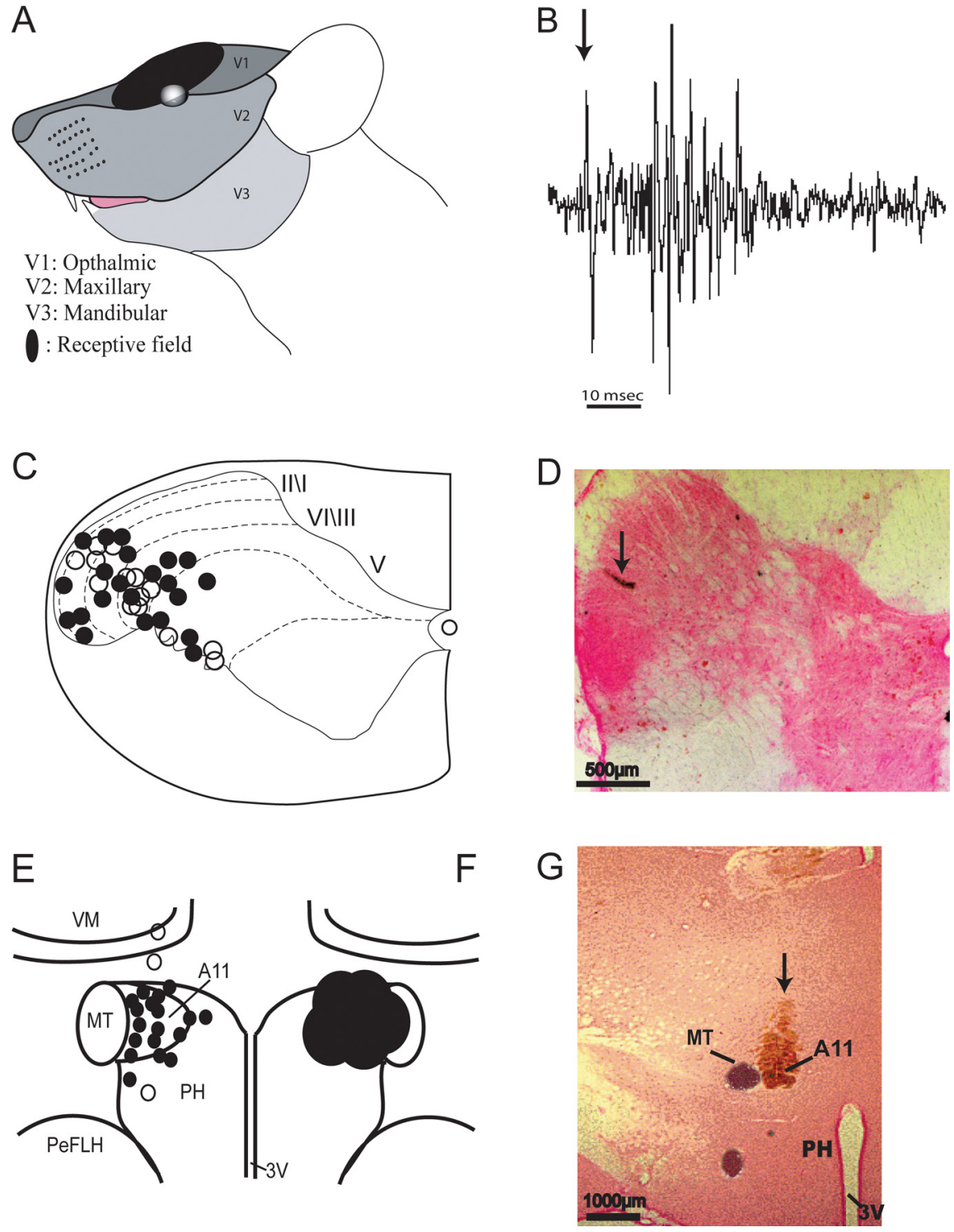

Figure 1. Localization and neuronal characteristics for experiments. $A$, The cutaneous receptive field of all neurons studied was in the first (ophthalmic) division of the trigeminal nerve. $\boldsymbol{B}$, An original tracing from a typical unit responding to middle meningeal artery/dural stimulation (the arrow represents the stimulus artifact). $C$, Summary of the locations of recording sites in the TCC. The locations were reconstructed from lesions (closed circles) or from microdrive readings (open circles). D, Example of a lesioned recording site in the dorsal horn (indicated by arrow; lesioned at $10-20 \mu \mathrm{A}, 20 \mathrm{~Hz}, 0.5 \mathrm{~ms}$ for $120 \mathrm{~s}$ ). The section was counterstained with Nuclear Fast Red (50X magnification). $\boldsymbol{E}$, Summary of the locations of stimulating sites in the A11 nucleus. The locations were constructed from lesions. The closed circles show effective stimulation; the open circles show ineffective stimulation. $\boldsymbol{F}$, Summary of the locations of lesioning sites in the $A 11$ nucleus. $\mathbf{G}$, Example of a lesioned stimulating site in the $A 11$ nucleus (indicated by arrow; lesioned at $100 \mu \mathrm{A}, 20 \mathrm{~Hz}, 0.5 \mathrm{~ms}$ for $120 \mathrm{~s}$ ). The section was counterstained with Nuclear Fast Red ( $12.5 \mathrm{X}$ magnification). mt, Mammillothalamic tract; $3 \mathrm{v}$, third ventricle; $\mathrm{PH}$, posterior hypothalamus; $\mathrm{PE}$, periventricular hypothalamic nucleus; VM, ventromedial thalamic nucleus.

bated in a solution of fluorescent secondary antibody (1:500 anti-mouse; Alexa Fluor 568; Invitrogen) in $\mathrm{PB}+$.

Receptor localization on fibers: dendrites versus axons

Where staining was located in fibers, we determined whether these fibers were dendrites or axons by double-staining sections using direct immunofluorescence with either an antibody specific to microtubuleassociated protein (MAP2) (1:500; raised in mouse; Millipore Bioscience Research Reagents) found in dendrites (Harada et al., 2002; Kuboyama et al., 2005), or with an antibody specific to axonal neurofilaments [neurofilament heavy protein $(\mathrm{NF}-\mathrm{H})]$ (1:2000; raised in chicken; Millipore Bioscience Research Reagents) (Perry et al., 1991; Shaw et al., 2005).
Controls

Negative control samples were obtained by omitting the primary antibodies and positive controls by staining brain areas known to contain the relevant receptor. Fluorescent staining was visualized using a Zeiss Axioplan Universal microscope (Zeiss).

\section{Results}

Effect of electrical stimulation of the A11 nucleus on neuronal firing in the

TCC in response to electrical

stimulation of the dura and

mechanical stimulation of the ophthalmic dermatome

Location and properties of the stimulating and recording electrodes

Extracellular recordings in the TCC were made from a total of 28 wide-dynamic range neurons ( $n=20$ rats), responsive to peri-middle meningeal artery/dural stimulation (8-16 V, 0.2-1.0 ms, 0.5-0.8 Hz), and with cutaneous receptive fields in the ophthalmic division of the trigeminal nerve (V1) (Fig. 1A). Neurons responding to dural stimulation responded at latencies of 5-23 ms with input from A $\delta$-fibers (Fig. $1 B)$. The location of these neurons ranged from superficial to deep layers (laminae I-V) of the dorsal horn of the TCC, at depths ranging from 200 to $1205 \mu \mathrm{m}$ (Fig. $1 C, D)$. Electrical stimulation in the A11 cell group (5-50 $\mu \mathrm{A}, 0.5 \mathrm{~ms}, 2-100 \mathrm{~Hz}$ ) was performed in 21 rats (Fig. $1 E$ ), and in each case the tip of the electrode track could be visualized in the A11 region (Fig. 1G).

Effect of electrical stimulation of A11 neurons on evoked neuronal firing in the TCC

Electrical stimulation of the A11 nucleus significantly inhibited firing in the TCC evoked by electrical stimulation of the dura by $14 \pm 1 \%\left(F_{(1.0,213.0)}=182.36 ; p<\right.$ $0.05 ; n=218$ units) and by noxious pinch stimulation of the ophthalmic dermatome by $25 \pm 1 \%\left(F_{(1.0,232.0)}=361.13\right.$; $p<0.05 ; n=232)$, but not by stimulation of the ophthalmic dermatome using innocuous brush $\left(F_{(1.0,161.0)}=2.49 ; p=\right.$ $0.116 ; n=161$ ), at all amplitudes from 5 to $50 \mu \mathrm{A}$, and within a frequency range of 2-50 Hz. In each case, using amplitude or frequency as a between-subjects factor did not show any significant differences. When all the data for A11 electrical stimulation were grouped, there was no significance across all frequencies $\left(F_{(1,216)}=0.21 ; p=0.65\right.$; for $2-50 \mathrm{~Hz} ; n=$ $218)$ or all amplitudes $\left(F_{(1,216)}=0.61 ; p=0.435\right.$; for $5-50 \mu \mathrm{A}$; $n=218)$. This was also the case with stimulation of the ophthalmic dermatome using both noxious pinch $\left(F_{(1,235)}=0.12, p=\right.$ 0.732 , for $2-50 \mathrm{~Hz}, n=237 ; F_{(1,235)}=3.11, p=0.079$, for $5-50$ $\mu \mathrm{A}, n=237)$ and innocuous brush $\left(F_{(1,164)}=0.0, p=0.99\right.$, for $2-50 \mathrm{~Hz}, n=166 ; F_{(1,164)}=3.23, p=0.074$, for $5-50 \mu \mathrm{A}, n=$ 166) for differences in amplitude and frequency; therefore, the data were pooled for subsequent analysis. 
Effect of intravenous administration of a $\mathrm{D}_{2}$ receptor antagonist on the inhibitory effect of A11 stimulation on neuronal firing in the TCC in response to dural electrical stimulation

After intravenous administration of the $\mathrm{D}_{2}$-like receptor antagonist $S$ - $(-)$ eticlopride (3 $\mathrm{mg} \mathrm{kg}^{-1}$ ), there was a transient drop in blood pressure by 30-34 $\mathrm{mmHg}$ that fully recovered after 12-14 s. The inhibitory effect of A11 stimulation on both durally evoked responses in the TCC and stimulation of the ophthalmic dermatome using noxious pinch was abolished at all time points from 5 to $40 \mathrm{~min}$ within the presence of the $\mathrm{D}_{2}$ receptor antagonist, and was no different to baseline response before A11 stimulation $\left(F_{(1.4,4.3)}=0.38, p\right.$ $=0.642$, for dural, $n=5 ; F_{(1.5,4.4)}=$ $1.15, p=0.372$, for noxious pinch, $n=$ $5)$. At $30 \mathrm{~min}$ the $\mathrm{D}_{2}$-like effect began to wear off and the A11 inhibitory effect returned, particularly in the case of noxious pinch evoked firing, which was reduced to $88 \pm 5 \%$ of baseline $\left(t_{(5)}=\right.$ 2.46; $p=0.07 ; n=5)$. As mentioned above, A11 stimulation had no effect on firing in the TCC in response to innocuous stimulation of the ophthalmic dermatome, this was not altered by administration of the $\mathrm{D}_{2}$ receptor antagonist, eticlopride (Fig. $2 A, B, E, F$ ).

After administration of the $\mathrm{D}_{2}$-like receptor antagonist alone, without A11 stimulation, there was a similar transient drop in blood pressure. Neuronal firing evoked by electrical stimulation of the dura mater was significantly facilitated at $5 \mathrm{~min}$, by $17 \pm 5 \%$ above baseline firing $\left(t_{(6)}=3.74 ; p<0.05 ; n=7\right)$. This dural evoked neuronal firing showed significant facilitation by $14 \pm 3 \%\left(F_{(15,30)}=2.73\right.$; $p<0.05$; $n=7$ ) over a 25 min period. Firing evoked by noxious pinch of the ophthalmic dermatome showed a trend for facilitation, although this was not significant over a $25 \mathrm{~min}\left(F_{(2.3,13.9)}=0.99\right.$; $p<0.409$; $n=7$ ) or a $40 \mathrm{~min}$ period.

Innocuous brush evoked firing of the ophthalmic dermatome continued to remain at baseline throughout (Fig. 2C). The intravenous saline control, without A11 stimulation, did not significantly affect dural, noxious pinch, or innocuous brush evoked firing in the TCC from 5 to $40 \mathrm{~min}$ (Fig. 2D).

\section{Effect of microinjection of L-glutamate into the A11 nucleus on evoked neuronal firing in the TCC}

Direct microinjection of $5 \mathrm{~mm}$ L-glutamate into the A11 nucleus significantly inhibited firing in the TCC evoked by dural stimulation, by a mean of $27 \pm 3 \%$ below baseline over a $40 \mathrm{~min}$ cohort $\left(F_{(2.5,12.6)}=5.01 ;{ }^{\star} p<0.05 ; n=6\right)$ and noxious pinch of the ophthalmic dermatome by a mean of $24 \pm 3 \%$ over a 30 min cohort $\left(F_{(2.9,14.6)}=2.57 ;{ }^{\star} p<0.05 ; n=6\right)$. Firing evoked
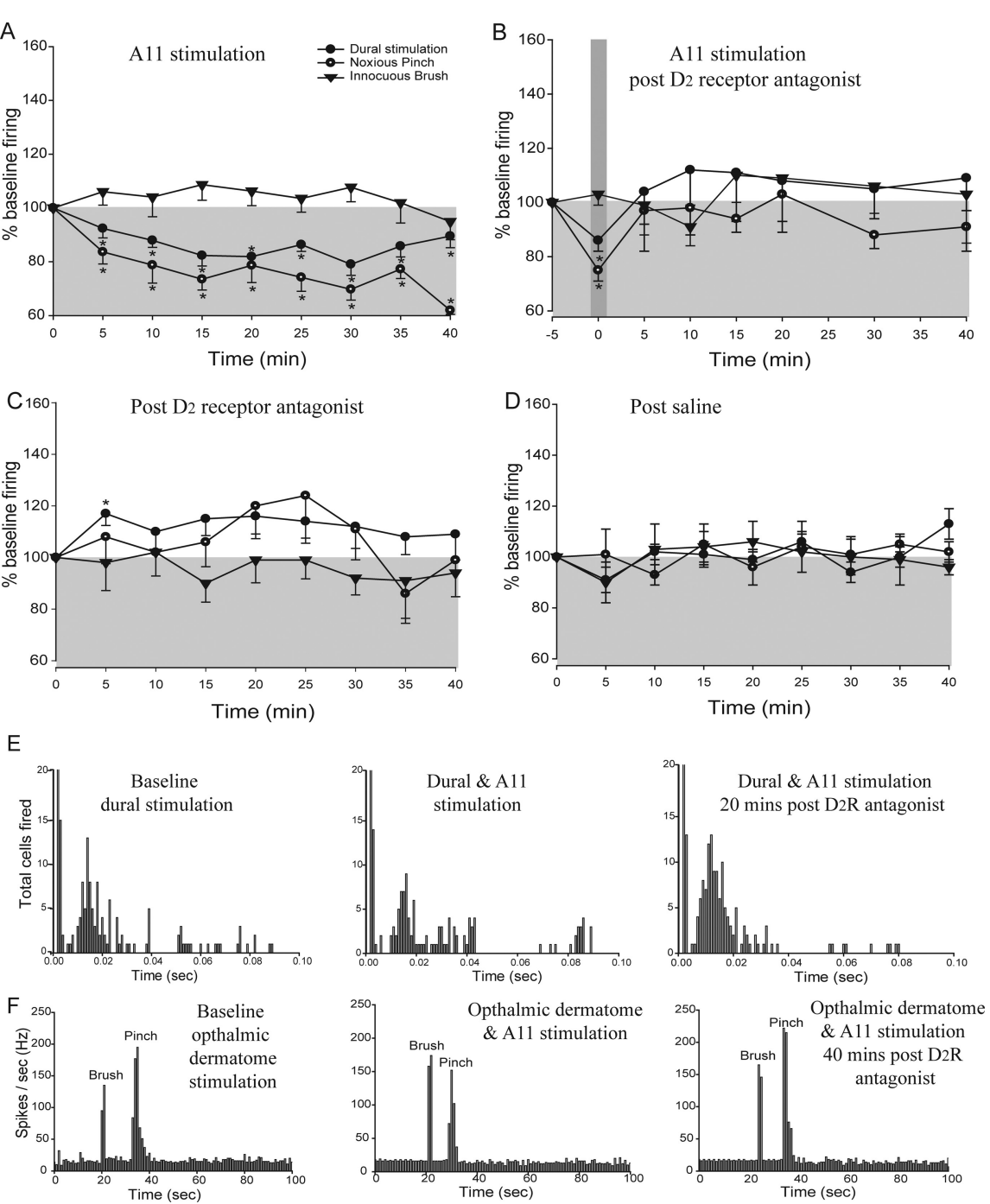

Figure 2. Effect of A11 electrical stimulation on neuronal firing in the TCC in response to electrical stimulation of the dural vasculature including middle meningeal artery and receptive field characterization using noxious pinch and innocuous brush. , Electrical stimulation of the A11 inhibits nociceptive evoked firing in the TCC. B Electrical stimulation of the A11 no longer 列 ( baseline responses to cutaneous stimuli (left), the inhibitory effects of A11 stimulation on noxious cutaneous evoked firing (middle), and then reversal of inhibition after intravenous $D_{2}$ receptor antagonist eticlopride (right). ${ }^{*} p<0.05$, significance compared with baseline response. Error bars indicate SEM.

by innocuous brush of the ophthalmic dermatome remained around baseline, with no significant effects to $40 \mathrm{~min}$. These results are comparable with the electrical stimulation data.

\section{Effect of electrical lesioning of the A11 nucleus on evoked firing in the trigeminocervical complex}

Location and properties of the stimulating, lesioning and recording electrodes

Extracellular recordings in the TCC were made from a total of eight wide-dynamic range neurons $(n=8$ rats) responsive to dural stimulation $(8-16 \mathrm{~V}, 0.2-1.0 \mathrm{~ms}, 0.5-0.8 \mathrm{~Hz})$, and with cutaneous receptive fields in the ophthalmic division of the trigeminal nerve. Neurons responding to electrical stimulation of the dura mater responded at latencies of 5-10 ms, so were receiving input from $A \delta$-fibers. In four of the eight cells recorded, 

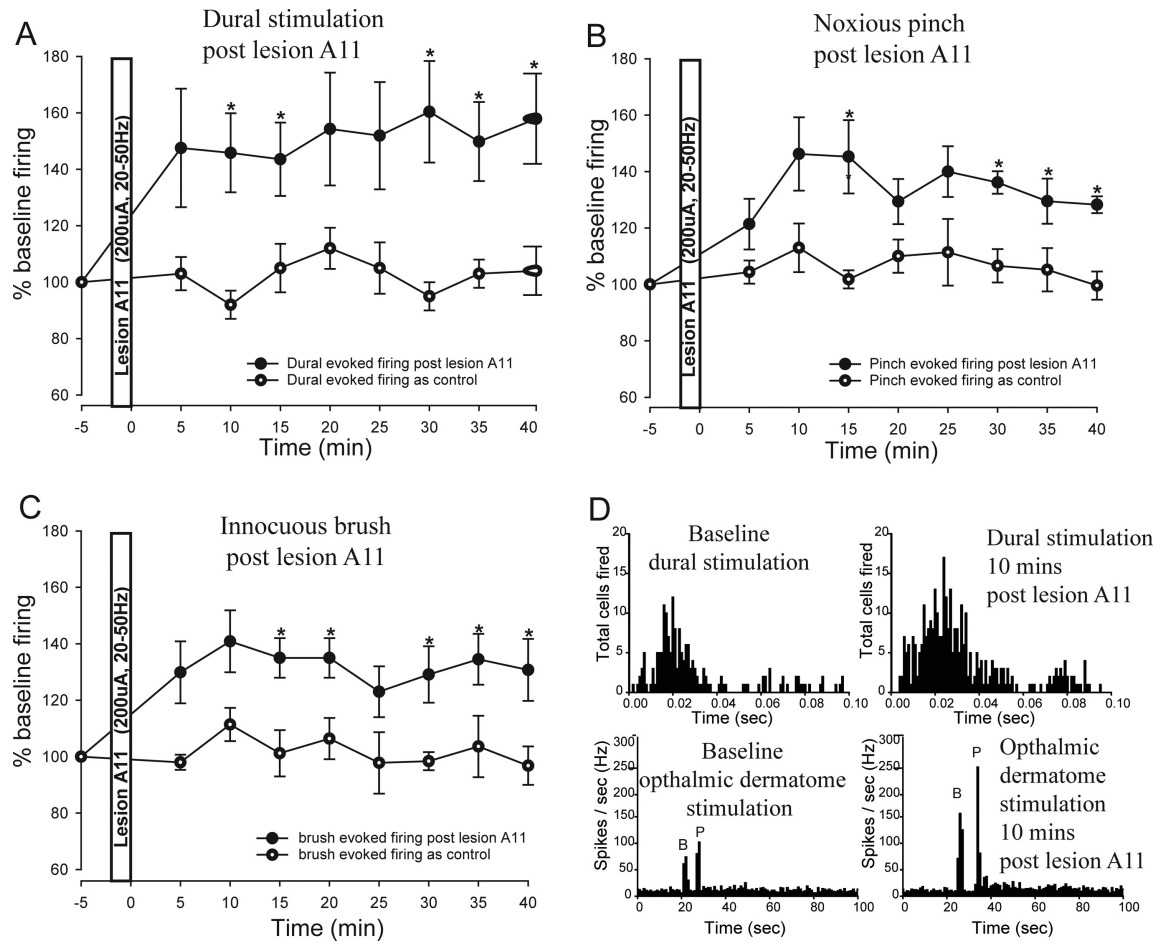

Figure 3. Effect of A11 lesioning on neuronal firing in the TCC in response to electrical stimulation of the dural vasculature including middle meningeal artery, and facial receptive field characterization using noxious pinch and innocuous brush. $A$, Lesioning of the $\mathrm{A} 11$ nucleus resulted in facilitation of dural-evoked firing in the $\mathrm{TCC}$, compared with sham experiments. $\boldsymbol{B}$, Lesioning of the $A 11$ nucleus resulted in facilitation of firing in the TCC evoked by noxious pinch of the ophthalmic dermatome. $C$, Lesioning of the $A 11$ nucleus resulted in facilitation of firing in the TCC evoked by of innocuous brush of the ophthalmic dermatome, compared with sham experiments. D, Poststimulus (top, dural stimulation) and peristimulus (bottom, cutaneous stimulation) histograms showing the facilitatory effect after A11 lesioning. For each input, baseline prelesion responses are seen on the left and postlesion effects on the right. ${ }^{*} p<0.05$, significance compared with baseline or sham. Error bars indicate SEM.

evoked firing consistent with input from C-fibers also was noted after lesioning of the A11, and this was stable for the remainder of the experiment. The location of these neurons ranged from superficial to deep layers (laminae I-V) of the dorsal horn of the TCC, at depths ranging from 105 to $913 \mu \mathrm{m}$ (Fig. 1C). Lesions of the A11 dopaminergic cell group $(200 \mu \mathrm{A}, 0.5 \mathrm{~ms}, 20-50 \mathrm{~Hz}$ for a total duration of 2-3 $\mathrm{min}$ ) were performed in each of these eight rats (Fig. $1 F$ ).

\section{Effect of electrical lesioning of A11 neurons on evoked neuronal firing in the TCC}

Electrical lesioning in the region of the ipsilateral A11 nucleus significantly facilitated firing in the TCC evoked by electrical stimulation of the dura mater by $48 \pm 6 \%\left(F_{(2.3,13.6)}=3.62\right.$; $p<0.05 ; n=8)$, by noxious pinch of the ophthalmic dermatome by $34 \pm 4 \%\left(F_{(3.5,17.4)}=3.49 ; p<0.05 ; n=8\right)$, and by innocuous brush of the ophthalmic dermatome by $29 \pm 5 \%$ $\left(F_{(4.0,23.8)}=2.43 ; p<0.05 ; n=8\right)$ across the 40 min cohort (Fig. $3 A-D)$. Placement of an electrode in the A11 with no electrical stimulation (data not shown) or lesion ( $\operatorname{sham;n=5)}$ did not show any significant changes from baseline across the cohort for durally evoked firing $\left(F_{(3.3,13.2)}=1.19 ; p=0.355\right.$; $n=5)$, noxious pinch evoked firing $\left(F_{(2.8,11.0)}=0.80 ; p=0.512\right.$; $n=5)$, or innocuous brush evoked firing $\left(F_{(2.9,11.7)}=0.63 ; p=\right.$ $0.61 ; n=5)$ across the $40 \mathrm{~min}$ of data collection.

Facilitation of durally evoked firing was significant at all time points, 5-40 min, when compared with baseline. Maximal facilitation was at $30 \mathrm{~min}, 58 \pm 16 \%$ above baseline $\left(t_{(7)}=3.53 ; p<\right.$
$0.05 ; n=8)($ Fig. $3 A$ ), although responses at all time points were similarly facilitated starting from 10 min after lesion. Facilitation of noxious pinch evoked firing in the TCC, was significant at all time points when compared with baseline, with the maximal effect at $10 \mathrm{~min}$, at $46 \pm 13 \%$ increase in firing $\left(t_{(7)}=3.76 ; p<0.05\right.$; $n=8$ ) (Fig. 3B). Facilitation of innocuous brush evoked firing in the TCC was significant at all time points, with the maximal facilitation also at $10 \mathrm{~min}$, at $41 \pm$ $14 \%$ increase $\left(t_{(7)}=3.08 ; p<0.05 ; n=8\right)$ (Fig. 3C).

At zero minutes after lesion, dural evoked firing and receptive fields were not significantly different from baseline.

\section{Immunohistofluorescence studies Immunofluorescent staining for $\mathrm{TH}$ (green) and CGRP (red) in the A11} Throughout the caudal A11/Spf region (4.64-5.16 mm), staining was as follows: the A1 1 contained two types of cells, larger TH (green) plus CGRP (red) cells, ranging in size from 22 to $46 \mu \mathrm{m}$, and smaller CGRP-only (red) cells, ranging in size from 13 to $27 \mu \mathrm{m}$. The Spf contained only small CGRP-only (red) cells, ranging in size from 12 to $25 \mu \mathrm{m}$. The A11 and Spf are therefore distinct from one another (Fig. 4A,B). Throughout the rostral A11 region (5.28-6.00 $\mathrm{mm}$ ), the A11 contained those same two types of cells as the caudal A11. There was no Spf at those levels (Fig. $4 D, E$ ). At all levels of the A11, there was greater density of CGRP-only neurons over TH plus CGRP neurons, with a 5:1 ratio.

Immunofluorescent staining for dopamine receptors in the TCC $\mathrm{D}_{2}$ receptors (green labeling), as positive controls, were clearly visible in the dorsal horn of the TCC. These were colocalized with $\mathrm{NeuN}$ (neuronal marker; red), thus indicating the presence of $\mathrm{D}_{2}$ receptors in neuronal cell bodies of the TCC (Fig. 5A). $\mathrm{D}_{4}$ receptors (green) were expressed throughout the entire rostrocaudal extent of the TCC, although $\mathrm{D}_{4}$ receptor density was not possible to establish, as the receptor was also seen in dense fibers (Fig. $5 B$ ). The $\mathrm{D}_{4}$ receptors in fibers were colocalized with NF-H (red) and not MAP2, and were thus identified as being in axons (Fig. $5 C$ ). Additionally $\mathrm{D}_{4}$-stained (green) cell bodies were visible at high magnification colocalized with $\mathrm{NeuN}$ (red), indicating the presence of $\mathrm{D}_{4}$ receptors in neuronal cell bodies in the TCC (Fig. 5D). $\mathrm{D}_{5}$ receptors (green) were located in cell bodies at a density of $118 \pm 16$ cells per hemisection and were also colocalized with NeuN, showing that these too exist in neuronal cell bodies of the TCC (Fig. $5 E, F)$. The $\mathrm{D}_{3}$ receptor was absent in the TCC, with the positive control of thalamus and hypothalamus (data not shown). The A11 nucleus did not express any dopamine receptors (data not shown).

\section{Discussion}

Electrical stimulation in the region of the A11 dopaminergic nucleus significantly inhibited firing in the trigeminocervical complex, evoked by electrical stimulation of the dura mater and 
noxious pinch of the ophthalmic dermatome, but not innocuous brush of the ophthalmic dermatome. This effect was reversed by a $\mathrm{D}_{2}$-family receptor antagonist. Moreover, lesioning of the A11 region facilitated dural and noxious pinch inputs and revealed otherwise silent nociceptors with C-fiber inputs. Furthermore, the data demonstrate that the A11 neurons under study are tyrosine hydroxylasepositive and dopamine $\beta$-hydroxylase-negative: true dopaminergic neurons. In addition, the A11 neurons stain for CGRP, whereas the close-by subparafascular nucleus does not. Last, we confirm the presence of $D_{2}, D_{4}$, and $D_{5}$ receptors but not $D_{3}$ receptors in the trigeminocervical complex, and the absence of any of dopamine receptors in the A11 nucleus. The data are consistent with the $\mathrm{A} 11$ providing a descending $\mathrm{D}_{2}$ receptor family-mediated tonic modulation of ophthalmic division trigeminal nociceptive afferents. The data are consistent with rat and cat spinal cord studies in which focal electrical stimulation in the region of the A11 dopamine cell group suppressed the nociceptive but not non-nociceptive responses of multireceptive neurons in the spinal cord dorsal horn (Fleetwood-Walker et al., 1988). The colocalization of CGRP in the A11 and the recently confirmed role for CGRP in migraine (Bigal et al., 2008; Ho et al., 2008), taken with other data on dopamine in migraine (Peroutka, 1997), suggest a possible role for the A11 in the disorder.

The inhibitory effect of the A11 on evoked firing in the TCC was abolished by the selective $\mathrm{D}_{2}$-like receptor antagonist, $S$ - $(-)$-eticlopride. As $\mathrm{D}_{2}$-like receptors $\left(\mathrm{D}_{2}, \mathrm{D}_{3}, \mathrm{D}_{4}\right.$ receptors) normally cause hyperpolarization and inhibit cell firing via an inhibition of cAMP formation (Missale et al., 1998), this suggests the A11 inhibitory effect is mediated by activation of $\mathrm{D}_{2}$-like receptors in the TCC. This interpretation is supported by data in the rat and cat spinal cord, in which the stimulus-evoked A11 effect was consistently and rapidly reversed by iontophoresis of a selective $\mathrm{D}_{2}$ receptor antagonist (sulpiride) in the vicinity of the dorsal horn neurons tested (Fleetwood-Walker et al., 1988). Furthermore, iontophoretically applied dopamine or a $\mathrm{D}_{2}$ receptor agonist (RU24213 [ $N$ - $n$-propyl- $N$-phenylethyl-4(3-hydroxyphenyl)ethylamine hydrochloride]) in the rat and cat spinal cord caused inhibition of nociceptive responses in these spinal cord neurons, reversed by a selective $\mathrm{D}_{2}$ receptor antagonist. In another study, Tamae et al. (2005) demonstrated with whole-cell patch-clamp recordings from spinal cord substantia gelatinosa neurons, that bath application of dopamine hyperpolarized the membrane potential of these neurons and suppressed stimulation-evoked action potentials. This effect was mimicked by a selective $\mathrm{D}_{2}$-like receptor agonist (quinpirole), and abolished by a selective $\mathrm{D}_{2}$-like receptor antagonist, but not by a $D_{1}$-like receptor antagonist (Tamae et al., 2005). Intravenous administration of a selective $\mathrm{D}_{2}$-like receptor antagonist, without A11 stimulation, significantly facilitated durally evoked firing in the TCC, suggesting a tonic descending inhibition. Previous studies have shown that eticlopride is effective at facilitating neuronal firing from 2 to 30 min (Henry et al., 1998; Ruskin et al., 1999; Morzorati and Marunde, 2006), and our results mirrored these findings.

Electrical lesioning in the region of the A11 significantly facilitated firing in the TCC, evoked by dural stimulation, noxious pinch, and innocuous brush. In four of eight experiments, evoked firing consistent with C-fiber inputs was uncovered that was not apparent during the prelesion baseline recordings, implying a tonic inhibitory role for A11. It is noteworthy that acute activation of G-protein-coupled receptors in CNS by either endogenous or exogenous ligands leads to internalization of those receptors from the surface of the neuron to the cytoplasm, which leads, within minutes, to decreased receptor abundance at the cell membrane (Mantyh et al., 1995; Dumartin et al., 2000). The reverse also applies; when faced with a decrease in extracellular ligands, excess G-protein-coupled receptors are trafficked from the cytoplasm to the cell membrane (Dumartin et al., 2000). This may contribute to the effect observed of a less substantial response to A11 stimulation compared with the facilitation since internalization of dopamine receptors caused by A11 stimulation would reduce the impact of excess dopamine signaling, whereas an increase in dopamine receptors 

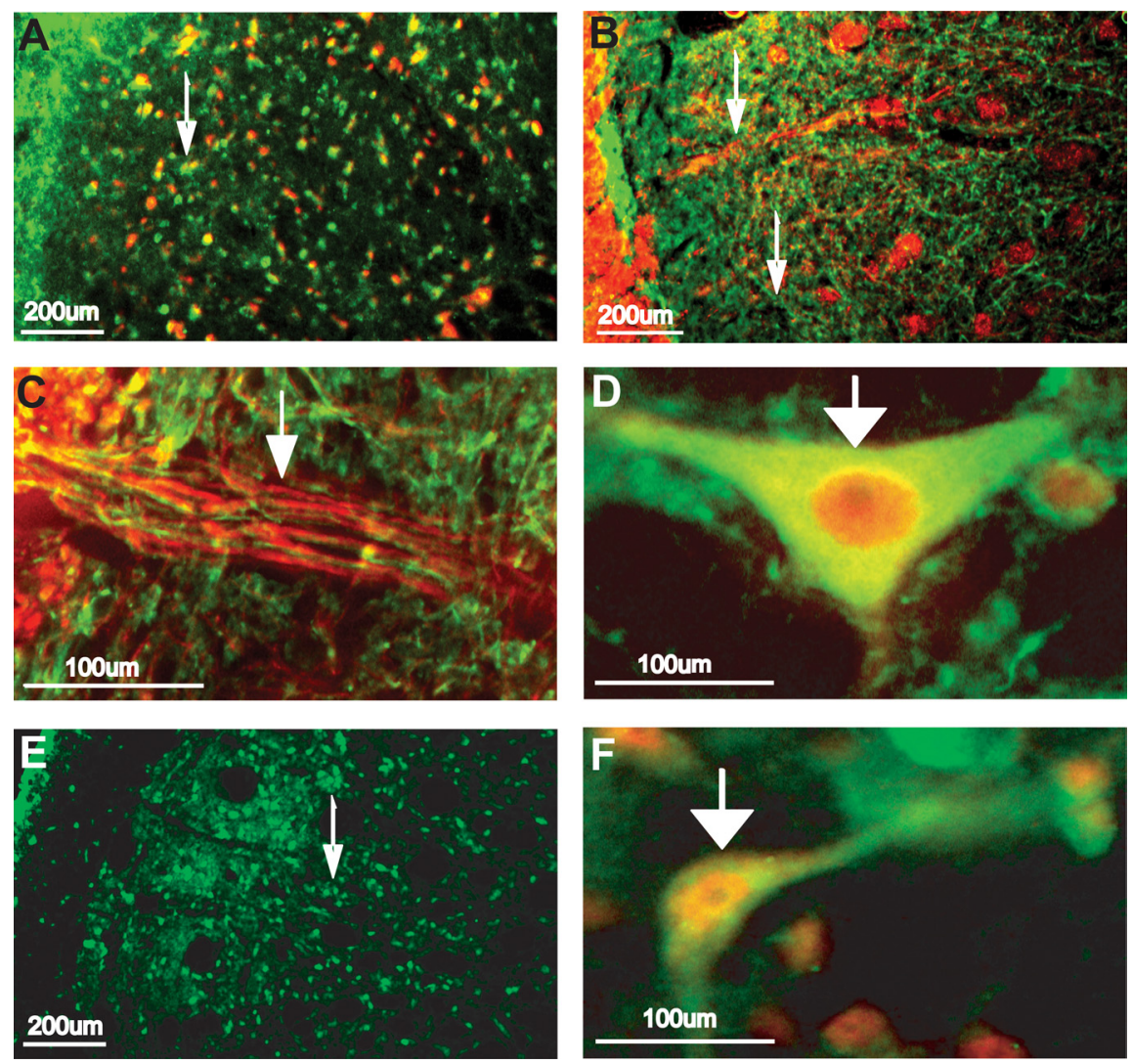

Figure 5. Immunofluorescent staining for dopamine receptors (all green labeling) in the TCC. $A$, $D_{2}$ receptors in the TCC, as positive control (green), colocalized with NeuN (neuronal marker) (red; $100 \times$ magnification). $\boldsymbol{B}, D_{4}$ receptors (green) in the TCC colocalized with $\mathrm{NF}-\mathrm{H}$, as a marker for axonal neurofilaments, identifying $\mathrm{D}_{4}$ receptors in axonal fibers (red; $100 \times$ magnification). C, High-power image of $D_{4}$ receptors (green) colocalized with NF-H (red; $400 \times$ magnification). $D$, High-power image of $D_{4}$ receptors (green) also colocalized with $\mathrm{NeuN}$ (red; $400 \times$ magnification), indicating their presence on neurons. $\boldsymbol{E}, \mathrm{D}_{5}$ receptors (green) in the TCC (100× magnification). $\boldsymbol{F}, D_{5}$ receptors (green) colocalized with NeuN (red; $400 \times$ magnification), indicating their presence in neurons. Examples in each image are indicated by arrows.

caused by A11 lesioning would be irrelevant without the presence of dopamine.

Innocuous brush evoked firing, which was unaffected during electrical stimulation of the A11, was significantly facilitated during lesioning of the A11 nucleus, suggesting a possible role in allodynia. Both peripheral and central sensitization is classically triggered by repeated high-frequency stimulation of neurons (Woolf and Salter, 2000; Bolton et al., 2005). In migraine, the trigeminal nerve is activated, or certainly perceived to be activated (Goadsby et al., 2002), and when trigeminal activation is not interrupted it has been hypothesized that peripheral sensitization rapidly progresses to central sensitization, causing cutaneous allodynia in the ipsilateral head (Burstein et al., 2000b). It is plausible for the A11 to have a role in this process. Dopamine is not the only inhibitory transmitted in the TCC (Bergerot et al., 2007), as notably 5HT (Longmore et al., 1997; Smith et al., 1998) is also present, and additional work would involve immunohistochemical staining to test for colocalization. Given that premonitory symptoms antecede pain by many hours (Giffin et al., 2003) and some, such as yawning, point to dopamine involvement (Peroutka, 1997), one could advance the hypothesis that these neurons may be involved in the early stages of an attack.

Electrical stimulation or lesioning in the A11 nucleus may have created current spread to adjacent brain regions (Ranck, 1975; McIntyre et al., 2004). Evoked firing in the TCC was significantly inhibited by direct injection of L-glutamate into the A11 nucleus, which implies that the inhibitory effect seen during stimulation of the A11 was attributable to direct activation of the A11 nucleus and not fibers of passage. Fibers of passage are not activated in this method nor are surrounding nuclei; as a consequence, the electrical stimulation data are likely to be A11 specific. It is also important to note that the A11 nucleus is the sole dopaminergic projection to the spinal cord; as such, the inhibitory response in the trigeminocervical complex is likely dopaminergic. Inhibition of the A11 effect with a dopamine D2 receptor antagonist is consistent with dopaminergic mediation at the level of the trigeminal nucleus.

Dahlstrom and Fuxe (1964) originally described the A11 as dopaminergic nucleus. These diencephalic neurons seem solely responsible for dopamine innervation of the dorsal horn and straddle the region of the mammillothalamic tract (Skagerberg et al., 1982). At one point, the A11 has been described as part of the Spf (Takada et al., 1988). The Spf is known to be CGRP-containing (Yasui et al., 1991; van Rossum et al., 1997; Coolen et al., 2003), and more recently it has been reported that the neighboring A11 also contains CGRP (Yasui et al., 1989, 1991). Finally, one study confirmed that A11 dopaminergic neurons were colocalized with CGRP (Orazzo et al., 1993). Immunohistofluorescence was therefore performed to confirm the distinction between the two. The Spf contained just CGRP-only neurons, whereas the A11 contained two types of neurons; dopamine colocalized with CGRP and also CGRP-only neurons, with CGRP-only neurons being approximately five times more abundant than dopamine/CGRP neurons. Hence all A11 dopaminergic cells were colocalized with CGRP. The data support a view that the A11 nucleus is distinct from the Spf.

Immunohistofluorescence also showed $\mathrm{D}_{4}$ and $\mathrm{D}_{5}$ receptors located in cell bodies in the TCC, in addition to the $\mathrm{D}_{1}$ and $\mathrm{D}_{2}$ receptors that have been previously identified (Bergerot et al., 2007). $\mathrm{D}_{4}$ belongs to the family of $\mathrm{D}_{2}$-like receptors, which, as demonstrated with the $\mathrm{D}_{2}$-like receptor antagonist eticlopride, are involved in the modulation of TCC firing. It is possible that one or both $\mathrm{D}_{2}$-like receptor subtypes are located postsynaptically on second-order neurons in the TCC, and mediate the observed inhibitory effect of dopamine on firing of second-order neurons from the TCC. Localization of receptors in the soma is potential evidence of postsynaptic activity, and this is supported by the study in which microiontophoresis of dopamine directly into the TCC produced inhibition of L-glutamate-evoked firing in the TCC (Bergerot et al., 2007). $\mathrm{D}_{4}$ receptors were also seen in axons. It may be important to note that none of the other dopamine receptors have been identified in fibers, including $D_{1}$ and $D_{2}$ receptors (Bergerot et al., 2007), suggesting the presence of autoreceptors in the TCC. Dopamine release is modulated by $\mathrm{D}_{2}$-like autoreceptors on dopamine terminals (Polak, 1971; Starke, 1977), so it could be that the $\mathrm{D}_{4}$-stained fibers represent 
autoreceptors belonging to descending A11 fibers. An increased frequency of certain alleles of the $D_{2}$ receptor gene has been found in migraine with aura (Peroutka, 1997) and offers an intriguing possible basis for an inherited dopaminergic basis for some part of the migraine phenotype.

The A11 is primarily known for its role in restless legs syndrome (RLS) (Allen et al., 2003), a sensorimotor disorder clinically characterized by uncomfortable and unpleasant sensations in the limbs (Ekbom, 1960), relieved by movement and worsened during periods of inactivity such as sitting or lying down. Dopamine, and specifically the $\mathrm{D}_{2}$-like receptor, was identified as having an important role in this disorder when it was found that low-dose dopaminergic agonists provided relief in patients with RLS (Hening et al., 1999; Montplaisir et al., 1999), whereas symptoms worsened when patients were given $\mathrm{D}_{2}$-like receptor antagonists, such as olanzapine (Kraus et al., 1999). Additionally, RLS patients exhibited static mechanical hyperalgesia to pinprick stimuli, which was alleviated by long-term dopaminergic treatment (Schattschneider et al., 2004; Tribl et al., 2005). In animal studies of RLS, $\mathrm{D}_{3} \mathrm{KO}$ mice exhibited excessive locomotor behavior (Clemens et al., 2006), and destruction of the diencephalospinal dopaminergic neurons of the A11 led to increased motor activity similar to RLS (Ondo et al., 2000). On this background, Rhode et al. (2007) report a comorbidity of RLS and migraine. There are some noteworthy comparisons: both syndromes are more common in females; both are affected by sleep; both are influenced by pregnancy, albeit in opposite directions; both have the same regional epidemiology (i.e., more common in Caucasians and less common in Asians); and both are clinically influenced by drugs acting at dopamine receptors. The overlap reinforces the utility of better understanding the A11 nucleus.

In conclusion, these studies present data showing that modulation of neurons in the A11 dopaminergic and CGRPergic nucleus affects trigeminovascular traffic, and this may be through a dopaminergic mechanism involving activation of inhibitory $\mathrm{D}_{2}-$ like receptors in the dorsal horn of the TCC. We also demonstrate that the A11 nucleus may act tonically to modulate trigeminal nociceptive transmission and that neurons in the A11 may modulate both nociceptive and non-nociceptive trigeminovascular traffic. Finally, it is possible that a dysfunction in the A11 nucleus in migraineurs may provide an explanation for the allodynia that frequently accompanies migraine.

\section{References}

Allen RP, Picchietti D, Hening WA, Trenkwalder C, Walters AS, Montplaisi J, Restless Legs Syndrome Diagnosis and Epidemiology Workshop at the National Institutes of Health, International Restless Legs Syndrome Study Group (2003) Restless legs syndrome: diagnostic criteria, special considerations, and epidemiology. A report from the Restless Legs Syndrome Diagnosis and Epidemiology Workshop at the National Institutes of Health. Sleep Med 4:101-119.

Bergerot A, Holland PR, Akerman S, Bartsch T, Ahn AH, MaassenVanDenBrink A, Reuter U, Tassorelli C, Schoenen J, Mitsikostas DD, van den Maagdenberg AM, Goadsby PJ (2006) Animal models of migraine. Looking at the component parts of a complex disorder. Eur J Neurosci 24:1517-1534.

Bergerot A, Storer RJ, Goadsby PJ (2007) Dopamine inhibits trigeminovascular transmission in the rat. Ann Neurol 61:251-262.

Bigal ME, Ashina S, Burstein R, Reed ML, Buse D, Serrano D, Lipton RB, AMPP Group (2008) Prevalence and characteristics of allodynia in headache sufferers: a population study. Neurology 70:1525-1533.

Bolton S, O'Shaughnessy CT, Goadsby PJ (2005) Properties of neurons in the trigeminal nucleus caudalis responding to noxious dural and facial stimulation. Brain Res 1046:122-129.

Burstein R, Cutrer MF, Yarnitsky D (2000a) The development of cutaneous allodynia during a migraine attack. Brain 123:1703-1709.
Burstein R, Yarnitsky D, Goor-Aryeh I, Ransil BJ, Bajwa ZH (2000b) An association between migraine and cutaneous allodynia. Ann Neurol 47:614-624.

Charbit AR, Holland PR, Goadsby PJ (2007) Stimulation or lesioning of dopaminergic A11 cell group affects neuronal firing in the trigeminal nucleus caudalis. Cephalalgia 27:605.

Clemens S, Rye D, Hochman S (2006) Restless legs syndrome: revisiting the dopamine hypothesis from the spinal cord perspective. Neurology 67:125-130.

Coolen LM, Veening JG, Petersen DW, Shipley MT (2003) Parvocellular subparafascicular thalamic nucleus in the rat: anatomical and functional compartmentalization. J Comp Neurol 463:117-131.

Dahlstrom A, Fuxe K (1964) Evidence for the existence of monoaminecontaining neurons in the central nervous system. I. Demonstration of monoamines in the cell bodies of brain stem neurons. Acta Physiol Scand Suppl 232:1-55.

Dumartin B, Jaber M, Gonon F, Caron MG, Giros B, Bloch B (2000) Dopamine tone regulates D1 receptor trafficking and delivery in striatal neurons in dopamine transporter-deficient mice. Proc Natl Acad Sci U S A 97:1879-1884

Ekbom KA (1960) Restless legs syndrome. Neurology 10:868-873.

Feindel W, Penfield W, McNaughton F (1960) The tentorial nerves and localization of intracranial pain in man. Neurology 10:555-563.

Fleetwood-Walker SM, Hope PJ, Mitchell R (1988) Antinociceptive actions of descending dopaminergic tracts on cat and rat dorsal horn somatosensory neurones. J Physiol 399:335-348.

Giffin NJ, Kowacs F, Libri V, Williams P, Goadsby PJ, Kaube H (2003) Effect of adenosine $A_{1}$ receptor agonist GR79236 on trigeminal nociception with blink reflex recordings in healthy human subjects. Cephalalgia 23:287-292.

Goadsby PJ, Edvinsson L, Ekman R (1988) Release of vasoactive peptides in the extracerebral circulation of man and the cat during activation of the trigeminovascular system. Ann Neurol 23:193-196.

Goadsby PJ, Edvinsson L, Ekman R (1990) Vasoactive peptide release in the extracerebral circulation of humans during migraine headache. Ann Neurol 28:183-187.

Goadsby PJ, Lipton RB, Ferrari MD (2002) Migraine-current understanding and treatment. N Engl J Med 346:257-270.

Harada A, Teng J, Takei Y, Oguchi K, Hirokawa N (2002) MAP2 is required for dendrite elongation, PKA anchoring in dendrites, and proper PKA signal transduction. J Cell Biol 158:541-549.

Headache Classification Committee of the International Headache Society (2004) The International Classification of Headache Disorders (second edition). Cephalalgia 24(Suppl 1):1-160.

Hening W, Allen R, Earley C, Kushida C, Picchietti D, Silber M (1999) The treatment of restless legs syndrome and periodic limb movement disorder. An American Academy of Sleep Medicine Review. Sleep 22:970-999.

Henry DJ, Hu XT, White FJ (1998) Adaptations in the mesoaccumbens dopamine system resulting from repeated administration of dopamine D1 and D2 receptor-selective agonists: relevance to cocaine sensitization. Psychopharmacology (Berl) 140:233-242.

Ho TW, Ferrari MD, Dodick DW, Galet V, Kost J, Fan X, Leibensperger H, Froman S, Assaid C, Lines C, Koppen H, Winner PK (2008) Efficacy and tolerability of MK-0974 (telcagepant), a new oral antagonist of calcitonin gene-related peptide receptor, compared with zolmitriptan for acute migraine: a randomised, placebo-controlled, parallel-treatment trial. Lancet 372:2115-2123.

Holden JE, Naleway E (2001) Microinjection of carbachol in the lateral hypothalamus produces opposing actions on nociception mediated by alpha(1)- and alpha(2)-adrenoceptors. Brain Res 911:27-36.

Holstege JC, Van Dijken H, Buijs RM, Goedknegt H, Gosens T, Bongers CM (1996) Distribution of dopamine immunoreactivity in the rat, cat and monkey spinal cord. J Comp Neurol 376:631-652.

Huang Q, Zhou D, Chase K, Gusella JF, Aronin N, DiFiglia M (1992) Immunohistochemical localization of the D1 dopamine receptor in rat brain reveals its axonal transport, pre- and postsynaptic localization, and prevalence in the basal ganglia, limbic system, and thalamic reticular nucleus. Proc Natl Acad Sci U S A 89:11988-11992.

Juhasz G, Zsombok T, Modos EA, Olajos S, Jakab B, Nemeth J, Szolcsanyi J, Vitrai J, Bagdy G (2003) NO-induced migraine attack: strong increase in plasma calcitonin gene-related peptide (CGRP) concentration and negative correlation with platelet serotonin release. Pain 106:461-470. 
Kraus T, Schuld A, Pollmächer T (1999) Periodic leg movements in sleep and restless legs syndrome probably caused by olanzapine. J Clin Psychopharmacol 19:478-479.

Kuboyama T, Tohda C, Komatsu K (2005) Neuritic regeneration and synaptic reconstruction induced by with anolide $\mathrm{A}$. Br J Pharmacol 144:961-971.

Lassen LH, Jacobsen VB, Haderslev PA, Sperling B, Iversen HK, Olesen J, Tfelt-Hansen P (2008) Involvement of calcitonin gene-related peptide in migraine: regional cerebral blood flow and blood flow velocity in migraine patients. J Headache Pain 9:151-157.

Levant B, McCarson KE (2001) $\mathrm{D}_{3}$ dopamine receptors in rat spinal cord: implications for sensory and motor function. Neurosci Lett 303:9-12.

Longmore J, Shaw D, Smith D, Hopkins R, McAllister G, Pickard JD, Sirinathsinghii DJ, Butler AJ, Hill RG (1997) Differential distribution of 5HT1D- and 5HT1B-immunoreactivity within the human trigeminocerebrovascular system: implications for the discovery of new antimigraine drugs. Cephalalgia 17:833-842.

Mantyh PW, Allen CJ, Ghilardi JR, Rogers SD, Mantyh CR, Liu H, Basbaum AI, Vigna SR, Maggio JE (1995) Rapid endocytosis of a G proteincoupled receptor: substance $P$ evoked internalization of its receptor in the rat striatum in vivo. Proc Natl Acad Sci U S A 92:2622-2626.

McIntyre CC, Grill WM, Sherman DL, Thakor NV (2004) Cellular effects of deep brain stimulation: model-based analysis of activation and inhibition. J Neurophysiol 91:1457-1469.

McKenna F, McLaughlin PJ, Lewis BJ, Sibbring GC, Cummerson JA, BowenJones D, Moots RJ (2002) Dopamine receptor expression on human Tand B-lymphocytes, monocytes, neutrophils, eosinophils and NK cells: a flow cytometric study. J Neuroimmunol 132:34-40.

Mignini F, Bronzetti E, Felici L, Ricci A, Sabbatini M, Tayebati SK, Amenta F (2000) Dopamine receptor immunohistochemistry in the rat choroid plexus. J Auton Pharmacol 20:325-332.

Missale C, Nash SR, Robinson SW, Jaber M, Caron MG (1998) Dopamine receptors: from structure to function. Physiol Rev 78:189-225.

Montplaisir J, Nicolas A, Denesle R, Gomez-Mancilla B (1999) Restless legs syndrome improved by pramipexole: a double-blind randomized trial. Neurology 52:938-943.

Morzorati SL, Marunde RL (2006) Comparison of VTA dopamine neuron activity in lines of rats selectively bred to prefer or avoid alcohol. Alcohol Clin Exp Res 30:991-997.

Nagatsu T, Stjärne L (1998) Catecholamine synthesis and release. Overview. Adv Pharmacol 42:1-14.

Olesen J, Diener HC, Husstedt IW, Goadsby PJ, Hall D, Meier U, Pollentier S, Lesko LM (2004) Calcitonin gene-related peptide (CGRP) receptor antagonist BIBN4096BS is effective in the treatment of migraine attacks. N Engl J Med 350:1104-1110.

Ondo WG, He Y, Rajasekaran S, Le WD (2000) Clinical correlates of 6-hydroxydopamine injections into A11 dopaminergic neurons in rats: a possible model for restless legs syndrome. Mov Disord 15:154-158.

Orazzo C, Pieribone VA, Ceccatelli S, Terenius L, Hökfelt T (1993) CGRPlike immunoreactivity in A11 dopamine neurons projecting to the spinal cord and a note on CGRP-CCK cross-reactivity. Brain Res 600:39-48.

Paxinos G, Watson C (2005) The rat brain in stereotaxic coordinates. San Diego: Elsevier Academic.

Peroutka SJ (1997) Dopamine and migraine. Neurology 49:650-656.

Perry MJ, Lawson SN, Robertson J (1991) Neurofilament immunoreactivity in populations of rat primary afferent neurons: a quantitative study of phosphorylated and non-phosphorylated subunits. J Neurocytol 20:746-758.

Polak RL (1971) Stimulating action of atropine on the release of acetylcholine by rat cerebral cortex in vitro. Br J Pharmacol 41:600-606.

Polgár E, Hughes DI, Arham AZ, Todd AJ (2005) Loss of neurons from laminas I-III of the spinal dorsal horn is not required for development of tactile allodynia in the spared nerve injury model of neuropathic pain. J Neurosci 25:6658-6666.

Ranck JB Jr (1975) Which elements are excited in electrical stimulation of mammalian central nervous system: a review. Brain Res 98:417-440.

Rhode AM, Hösing VG, Happe S, Biehl K, Young P, Evers S (2007) Comorbidity of migraine and restless legs syndrome-a case-control study. Cephalalgia 27:1255-1260.

Ruskin DN, Bergstrom DA, Walters JR (1999) Multisecond oscillations in firing rate in the globus pallidus: synergistic modulation by D1 and D2 dopamine receptors. J Pharmacol Exp Ther 290:1493-1501.

Schattschneider J, Bode A, Wasner G, Binder A, Deuschl G, Baron R (2004) Idiopathic restless legs syndrome: abnormalities in central somatosensory processing. J Neurol 251:977-982.

Selby G, Lance JW (1960) Observations on 500 cases of migraine and allied vascular headache. J Neurol Neurosurg Psychiatry 23:23-32.

Shaw G, Yang C, Ellis R, Anderson K, Parker Mickle J, Scheff S, Pike B, Anderson DK, Howland DR (2005) Hyperphosphorylated neurofilament NF-H is a serum biomarker of axonal injury. Biochem Biophys Res Commun 336:1268-1277.

Skagerberg G, Björklund A, Lindvall O, Schmidt RH (1982) Origin and termination of the diencephalo-spinal dopamine system in the rat. Brain Res Bull 9:237-244

Smith D, Shaw D, Hopkins R, McAllister G, Hill R, Sirinathsinghji D, Longmore J (1998) Development and characterisation of human 5-HT1B- or 5-HT1D-receptor specific antibodies as unique research tools. J Neurosci Methods 80:155-161.

Starke K (1977) Regulation of noradrenaline release by presynaptic receptor systems. Rev Physiol Biochem Pharmacol 77:1-124.

Storer RJ, Akerman S, Goadsby PJ (2004) Calcitonin gene-related peptide (CGRP) modulates nociceptive trigeminovascular transmission in the cat. Br J Pharmacol 142:1171-1181.

Strassman AM, Raymond SA, Burstein R (1996) Sensitization of meningeal sensory neurons and the origin of headaches. Nature 384:560-564.

Takada M, Li ZK, Hattori T (1988) Single thalamic dopaminergic neurons project to both the neocortex and spinal cord. Brain Res 455:346-352.

Tamae A, Nakatsuka T, Koga K, Kato G, Furue H, Katafuchi T, Yoshimura M (2005) Direct inhibition of substantia gelatinosa neurones in the rat spinal cord by activation of dopamine D2-like receptors. J Physiol 568:243-253.

Tribl GG, Sycha T, Kotzailias N, Zeitlhofer J, Auff E (2005) Apomorphine in idiopathic restless legs syndrome: an exploratory study. J Neurol Neurosurg Psychiatry 76:181-185.

van Rossum D, Hanisch UK, Quirion R (1997) Neuroanatomical localization, pharmacological characterization and functions of CGRP, related peptides and their receptors. Neurosci Biobehav Rev 21:649-678.

Wolf HK, Buslei R, Schmidt-Kastner R, Schmidt-Kastner PK, Pietsch T, Wiestler OD, Blümcke I (1996) NeuN: a useful neuronal marker for diagnostic histopathology. J Histochem Cytochem 44:1167-1171.

Woolf CJ, Salter MW (2000) Neuronal plasticity: increasing the gain in pain. Science 288:1765-1769.

Workman BJ, Lumb BM (1997) Inhibitory effects evoked from the anterior hypothalamus are selective for the nociceptive responses of dorsal horn neurons with high- and low-threshold inputs. J Neurophysiol 77:2831-2835.

Yasui Y, Saper CB, Cechetto DF (1989) Calcitonin gene-related peptide immunoreactivity in the visceral sensory cortex, thalamus, and related pathways in the rat. J Comp Neurol 290:487-501.

Yasui Y, Saper CB, Cechetto DF (1991) Calcitonin gene-related peptide (CGRP) immunoreactive projections from the thalamus to the striatum and amygdala in the rat. J Comp Neurol 308:293-310. 